\title{
Reviving Tourism Industry Amid Covid-19: An Interest-based Policy-making Approach
}

\author{
Jialang $\mathrm{He}^{1,{ }^{*}, \mathrm{a}, \dagger}$, Zhijie Jin ${ }^{2, *}, \mathrm{~b}, \dagger$, Hongyi Zhu ${ }^{3, *, c, \dagger}$ \\ ${ }^{1}$ Storrs Campus, University of Connecticut, 06269, US; \\ ${ }^{2}$ Business School, University of Birmingham, Birmingham, B15 2TY, UK; \\ ${ }^{3}$ University of Adelaide, 5005, Australia. \\ *Corresponding author.Email: ${ }^{*} 3457542776 @ q q . c o m,{ }^{b} z$ xj998@student.bham.ac.uk, \\ ca1838274@student.adelaide.edu.au \\ These authors contributed equally.
}

\begin{abstract}
The Covid-19 health crisis has engendered detrimental influences on the tourism industry, generating substantial losses of jobs and economic benefits. In this context, restoring tourism businesses is becoming increasingly crucial for the revival of the economy. Nevertheless, during the pandemic, the invested interests of tourism sites can be somewhat contradictory to the interests of the local governments, which focus more on containing the virus transmission. Facing this dilemma, this study aims to review the interests of tourism sites and governments. Based on our analysis, it is found that their interests can be mediated through appropriate policy-making. Consequently, an array of recommendations to reach a win-win situation for both parties are put forward. This study would practically contribute to the management of the tourism industry during the pandemic and theoretically shed light on the application of interest-based theories in the social governance field.
\end{abstract}

Keywords: Interest-based theory, Social governance, Hospitality and tourism industry, Tourism revival, Covid-19 pandemic.

\section{INTRODUCTION}

The negative impacts of the Covid-19 pandemic on the global hospitality and tourism industry are immense. Since the outbreak of this health crisis, more than $95 \%$ of the tourism sites in the world have to somehow shut down or impose certain restrictions to constrain the virus transmission. More than that, due to the travel restrictions imposed by the governments, travelers' mobilities have been critically confined [1]. According to the statistics put forward by the UNWTO, the global tourism revenue has been decreased by around $80 \%$ in the year 2020, and the recovery of the tourism industry will not be fully achieved until the year 2024. In such a context, the hospitality and tourism industry has been considered one of the most hit economic sectors [1].

There is no doubt that the major tourist attractions in the world have been encountering huge challenges. One of which is the loss of the tourism revenue that makes the attractions formidable to continue operating. More than the financial strikes, since there is no income during the lockdown period, the tourism sites must lay off the staff to cut costs. As the tourism industry is labor-intensive, massive loss of service jobs may simultaneously create a number of social problems such as the unemployment issue [2]. In this situation, Gloria Guevara, the person in charge of the World Travel and Tourism Council, has been lobbying governments to offer support to business players in the tourism industry by especially mentioning that these potential job losses bring a real and profound worry millions of families around the world.

However, even though they are well-noticed with respect to those self-evident negative impacts brought by the pandemic to the tourism industry, their budgets have also been greatly constrained for almost all the governments in the world. More than that, they have been suffering from intensive pressure from the public to contain the virus while ensuring the economic conditions are good enough to sustain people's normal life [3]. Huge complexities have been put into the governments' decision-making process, and all of these make the support from the public sector to the tourism industry even harder and complicated [4]. 
Nonetheless, while there are still tremendous uncertainties lingering due to the mitigation of the pandemic and the soaring vaccination coverage rates, both the tourism attractions and local governments likely commence collaboration to re-open the tourism sectors [5]. However, there might still exist contradictory interests for the tourism stakeholders and local government in this process [5]. For instance, the government has to control the disease and improve the people's happiness in general, while the tourism attractions would concentrate more on the monetary benefits. Amid such a situation, it is believed that interestbased policy-making measures can be applied to seek a win-win solution to solve the problems amid the pandemic time.

Thereby, this review study attempts to find a way to satisfy the needs of both sides by trying to draft measures to increase tourism revenue based on controlling the epidemic. As to the article's structure, the following sections would first review the invested interests of both the scenic spots and local governments. After comparing the interests from both sides, some recommendations can be proposed for both the local governors and the managers of the tourism sites.

\section{INTERESTS FOR THE TOURISM PLAYERS AMID THE PANDEMIC}

The hospitality and tourism industry is composed of numerous players, including tourism attractions, transportation, accommodation, food and beverage, retailing, etc., providing crucial service functions including but not limited to receiving tourists, providing transportation, accommodation, sightseeing, catering, shopping, and entertainment. Since the outbreak of the epidemic in 2020, the tourism industry has been seriously hit. The major functions have stopped running, and the sustainability of their operation has stagnated.

According to previous studies, the interests of tourism stakeholders can be divided into three dimensions in such a different times. First and foremost, their interest is to maintain the operational feasibility through proper facilities maintenance and staff retention. It can be said that the pandemic will essentially harm the tourism infrastructure and superstructure [6]. For example, the maintenance fees can be extremely high for those artificial tourism sites without tourists visiting. Besides, if the staff is fired due to no payroll budget, the recruitment fee would also be very high when re-opening.

For the second dimension, their interest is to gradually open the attractions when the pandemic is mitigated by significantly increasing the number of tourists. This definitely needs approval from the law and regulation-making sectors, namely the government. Only if the government allows people to travel and gather together can the tourism attractions open their gates to welcome tourists [7].

Finally, the third dimension of their interest would focus on restoring their tourism revenue and gaining profits. To achieve this goal, it needs a total re-opening or a new normal of the tourism industry. And this would become the ultimate objective or aspiration of the tourism players [7]. While it is not highly feasible for the time being, this would be the direction of future endeavors for tourism players and local tourism governors.

All in all, it can be found that the interests of tourism players are mainly monetary-based. Although their interests can be correlated with the social benefits such as the employment condition, the major interests of tourism attractions have to be pertaining to the economic dimension. Therefore, in the ensuing policy-making, local governments have to be conscious of this aspect.

\section{INTERESTS FOR THE LOCAL GOVERNMENTS AMID THE PANDEMIC}

Since the outbreak of the pandemic, the governments have been under great pressure. It is not hard to imagine that if people cannot work and entertain, there would be tremendous troubles, not to mention that the epidemic situation is still very unstable. Newly infected people may emerge at any time.

In addition to challenges in people's psychology and health conditions, more challenges are embedded into the damaged local economy, posing threats to people's daily lives. Under this situation, it can be said that the governments' interests are far more complex than tourism business players. As per previous studies, the government's interests can be simplified by three aspects: economic interests, health interests, and social-cultural interests $[7,8]$.

The first aspect is regarding the economic benefits. Within this domain, the specific interests of the government can be heterogeneous, including but not limited to restore taxes revenue to ensure the employment rate and guarantee that various industries can run without going bankrupt. The central goal of the government is to make sure that the local economy can be sustained or at least survived until the pandemic is over [8].

Second, during the pandemic time, the government must pay efforts to limit the transmission of the virus by implementing stringent confinement measures, such as mobility lockdown and business shutdown. More than that, the government has to ensure their hospitals can handle the volume of patients [8]. For now, they also need to push the vaccination plan. All in all, they do undertake strong responsibilities in coping with the covid-19 health crisis by preventing more infections from happening and ensuring herd immunity can be achieved as soon as possible [9]. 
At last, the COVID-19 pandemic is a health crisis and a social crisis [2]. This pandemic will create harm to people's mental health. Therefore, ensuring people's psychological benefits also turns into a mandatory task for the government. This aspect would be highly relevant with regard to the re-opening of those places for people's entertainment and leisure to relieve the pressure caused by the epidemic, which provides a basis for an interestbased approach of tourism-policy making.

\section{THE INTEREST-BASED APPROACH FOR TOURISM POLICY-MAKING}

While both the tourism destinations and the governments definitely have more roles to take, the above two sections delineate the major interests for these two parties that can be referred to in the policy-making process. As believed by the author, the following Figure 1 visually shows the interests of the tourist attractions and the government and what the future mechanism of policymaking will look like.

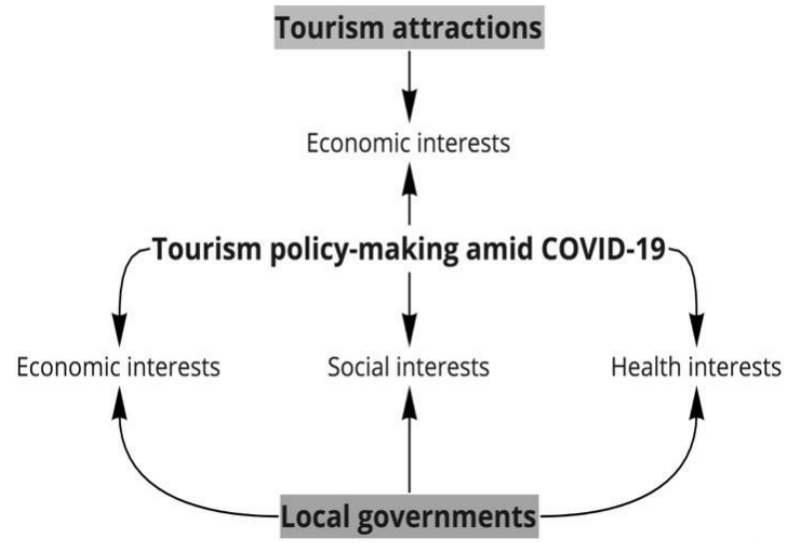

Figure 1. Mechanism of tourism policy-making through interest-based approach

As can be further manifested in Figure 1, there is a huge overlap with respect to their interests. In accordance with the rules of interest-based policy-making, relevant regulators and industrial players should then perform well in line with agreed and consistent places [10]. In other means, future policy-making should centralize on the economic benefits and ensure meeting the social and health interests of the government. Consequently, to implicate the real practice, the next section attempts to discuss how interest-based theories can shed light on the revival of the tourism industry by formulating measures that can meet the needs of both sides while allowing the tensions to be acceptable.

\section{MEASURES TO ACCOMMODATE THE INTERESTS OF BOTH SIDES}

As can be found from the above analysis, it is presumed that, based on the agreed interests of both sides, the tourism business players and the government can reach cooperation and make benefits together. Therefore, this section would discuss some feasible solutions from the two parties, namely the scenic spots and the government, to achieve a win-win situation under the premise of economic gains and effective epidemic prevention and control.

To begin with, from the perspective form the scenic spots, they must obey the health rules imposed by the national health authorities to meet the health requirements. For instance, they can limit the flow of visitors. The reason is that too many tourists will increase the risk of being infected by the virus. Once there is an outbreak, the scenic area will not operate for a long period, which will undoubtedly lead to a serious setback in revenue.

In addition to the tourist flow limitation, it is necessary to implement an array of health-related measures. In other words, the scenic spots have to perform well in terms of epidemic prevention and control. The person in charge of the scenic spot is suggested to purchase pertinent health prevention facilities, send out patrols, set up daily inspections, strengthen the management of epidemic prevention and recruit more staff, and so forth. While these would generate lots of costs, it is necessary to avoid the risk of virus infection to meet the health interest.

This measure would also, in turn, benefit economic interest. Based on extant studies, the tourists would prefer to go traveling when the perceived health guarantee is high. That being said, as long as the tourists can see that the safety of the scenic spot is improved, they would set out to start their journey. Hence, for the sake of epidemic prevention and control, scenic spots should merely accept tourists who provide nucleic acid certificates or vaccinations.

Other than those health-related measures, it would be important to provide some monetary stimulus for the potential tourists. For example, tourism attractions can reduce ticket prices. After a year's epidemic, even if people want to travel, their economic situation may not be as optimistic as before. At this time, discounts or concessions will make more people can afford the travelling costs. In this way, it is expected to reach greater economic benefits for tourism attractions.

Aside from the measures made by scenic spots, to compensate for the sacrifice of the scenic area, the government also needs to accommodate the tourism attractions' interests by providing preferential policies to the scenic area. First, the government may require tourists to stay in the designated scenic hotel. On the one hand, it can improve the income of the scenic spot; conversely, it is convenient for tourists to carry out the necessary daily safety and health examination. 
Second, the government can help the tourism industry carry out publicity in the form of free broadcasting of promotional videos on TV and various internet channels. Through this method, the government can harness its advantages in terms of promotional functions to enhance the destination image and endorse the tourism sites.

The third measure is that the government can reduce the tourism tax conditionally. For example, if the total revenue of the tourism industry this year does not reach two-thirds of that before the outbreak of the epidemic, the government would only charge $50-70 \%$ of the standard tax to indirectly increase the overall revenue of the tourism industry. More than the tax reduction, the government can even provide funding to support the tourism industry.

Then, for those who want to travel but are worried about safety, the government is suggested to provide them with free vaccination and nucleic acid testing. This will play a protective role in people's travel and normal life. Accordingly, for the sake of epidemic prevention and control, each scenic spot will only receive tourists who have been injected with the COVID-19 vaccine or provided with a nucleic acid testing certificate.

\section{CONCLUSION}

In conclusion, this study analyzes the interests of the tourist attractions, and local governments are. As a result of the analysis, it is found that their interests are overlapping with regard to the monetary and health benefits. Furthermore, it is deemed that their needs can be appropriately accommodated. Thus, an array of recommendations for both the scenic spots and local governments is proposed in the above section.

While according to different contexts, distinct measures have to be implemented, this article provides a general guideline for the tourism practitioners to be referred to to achieve the interests of both sides. In other words, it can be clearly found that the interests between the tourism attractions and local governments are essentially consistent, which offers a foundation to reopen the tourism industry and to achieve monetary and social benefits while containing the virus transmission.

However, it should also be noted that some potential risks may arise in the implementation process. For example, there is no guarantee that scenic spots can fully comply with the requirements. For example, some scenic spots could violate epidemic prevention regulations and allow more than the limited number of tourists to enter the scenic area to make more profit. Or the scenic spot is unable to check the nucleic acid test and vaccine information of tourists as required. Therefore, no matter how perfect the system is, there will be potential risks.

Thus, to sum up, it is crucial to realize that the embedded interests can be ever-changing, and the actual measures should be made on a dynamic basis. Nonetheless, this article demonstrates an interest-based angle to evaluate the current situation for the tourism stakeholders and local governors to make decisions amid the pandemic time. For future studies, they need to dig into the specific tourism destinations to develop the best practices for the revival of the tourism industry and how interest-based policy-making can reach a win-win situation for both the tourism players and the local governments.

\section{REFERENCES}

[1] Kreiner, N. C., \& Ram, Y. (2020). National tourism strategies during the Covid-19 pandemic. Annals of tourism research.

[2] Qiu, R. T., Park, J., Li, S., \& Song, H. (2020). Social costs of tourism during the COVID-19 pandemic. Annals of Tourism Research, 84, 102994.

[3] Higgins-Desbiolles, F. (2020). The "war over tourism": challenges to sustainable tourism in the tourism academy after COVID-19. Journal of Sustainable Tourism, 29(4), 551-569.

[4] Kaushal, V., \& Srivastava, S. (2021). Hospitality and tourism industry amid COVID-19 pandemic: Perspectives on challenges and learnings from India. International Journal of Hospitality Management, 92, 102707.

[5] Yeh, S. S. (2020). Tourism recovery strategy against COVID-19 pandemic. Tourism Recreation Research, 1-7.

[6] Sigala, M. (2020). Tourism and COVID-19: Impacts and implications for advancing and resetting industry and research. Journal of business research, $117,312-321$.

[7] Lew, A. A., Cheer, J. M., Haywood, M., Brouder, P., \& Salazar, N. B. (2020). Visions of travel and tourism after the global COVID-19 transformation of 2020.

[8] Brouder, P., Teoh, S., Salazar, N. B., Mostafanezhad, M., Pung, J. M., Lapointe, D., ... \& Clausen, H. B. (2020). Reflections and discussions: tourism matters in the new normal post COVID-19. Tourism Geographies, 22(3), 735-746.

[9] Gössling, S., Scott, D., \& Hall, C. M. (2020). Pandemics, tourism and global change: a rapid assessment of COVID-19. Journal of Sustainable Tourism, 29(1), 1-20.

[10] Duro, J. A., Perez-Laborda, A., Turrion-Prats, J., \& Fernández-Fernández, M. (2021). Covid-19 and tourism vulnerability. Tourism Management Perspectives, 38, 100819. 